Supplementary Information:

\title{
Quasi-Phthalocyanine Conjugated Covalent Organic Frameworks with Nitrogen-Coordinated Transition Metal Centres for High- Efficiency Electrocatalytic Ammonia Synthesis
}

Authors: Minghang Jiang,,$^{\dagger,, \S}$ Linkai Han,,$^{\dagger, \perp}$ Peng Peng, ${ }^{\perp}$ Yi Hu,,${ }^{\ddagger}$ Yan Xiong,,$\$$

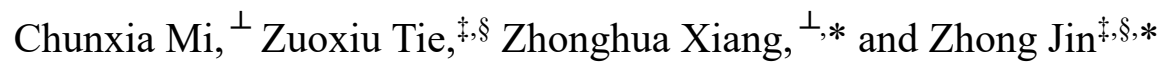

\section{Affiliations:}

$\$$ MOE Key Laboratory of Mesoscopic Chemistry, MOE Key Laboratory of High Performance Polymer Materials and Technology, Jiangsu Key Laboratory of Advanced Organic Materials, School of Chemistry and Chemical Engineering, Nanjing University, Nanjing, Jiangsu 210023, China.

$\S$ Shenzhen Research Institute of Nanjing University, Shenzhen 518063, China.

${ }^{\perp}$ Beijing Advanced Innovation Center for Soft Matter Science and Engineering, State Key Laboratory of Organic-Inorganic Composites, Beijing University of Chemical Technology, Beijing 100029, China.

$\dagger$ These authors contributed equally: Minghang Jiang, Linkai Han.

* Address correspondence to xiangzh@mail.buct.edu.cn or to zhongjin@nju.edu.cn. 


\section{EXPERIMENTAL SECTION}

Chemicals and Materials. All chemicals in this work were purchased from commercial sources with analytical reagent (AR) grade and used as received without further processing. Benzene-1,2,4,5-tetracarbonnitrile (BTC) was obtained from Ark Pharm, Inc. 1,8-Diazabicyclo $(5,4,0)$ undec-7-ene (DBU) and glycol solvent were received from $\mathrm{J} \& \mathrm{~K}$ Chemical Technology. $\mathrm{TiCl}_{4}$ was purchased from Beijing Chemical Works and Aladdin Company. Nafion solution (5 wt. \%) was purchased from DuPont China Holding Co., Ltd. Trisodium citrate dihydrate $\left(\mathrm{C}_{6} \mathrm{H}_{5} \mathrm{Na}_{3} \mathrm{O}_{7} \cdot 2 \mathrm{H}_{2} \mathrm{O}\right)$, sodium salicylate $\left(\mathrm{C}_{7} \mathrm{H}_{5} \mathrm{NaO}_{3}\right)$, salicylic acid $\left(\mathrm{C}_{7} \mathrm{H}_{6} \mathrm{O}_{3}\right)$, hydrazine hydrate $\left(\mathrm{N}_{2} \mathrm{H}_{4} \cdot \mathrm{H}_{2} \mathrm{O}\right)$ and para-(dimethylamino) benzaldehyde were purchased from Nanjing Chemical Reagent Co., Ltd. Carbon paper (CP, Toray TGP-H-060) was purchased from Toray Industries, Inc. Ultrapure deionized water $(18.2 \mathrm{~m} \Omega \cdot \mathrm{cm}$, Millipore SAS, France) was used for all experiments.

Synthesis of pristine COF and Ti-COF, Cu-COF and Co-COF samples. Pristine COF was prepared by following our previous research works ${ }^{34,35}$. Briefly, Benzene1,2,4,5-Tetracarbonitrile (BTC) and 1, 8-Diazabicyclo $(5,4,0)$ undec-7-ene (DBU) as the monomers and the catalysts, respectively. $2 \mathrm{mmol}$ BTC and $0.01 \mathrm{mmol}$ DBU were dissolved in $20 \mathrm{~mL}$ ethylene glycol and kept at $180{ }^{\circ} \mathrm{C}$ for $15 \mathrm{~min}$ in a Discover SPMicrowave Synthesizer to synthesize the pristine COF. Ti-COF was also synthesized using the same method as the pristine COF but with the addition of $1 \mathrm{mmol} \mathrm{TiCl}_{4}$. In this process, the assembly of BTC with Ti riveted in the centre and finally constructed into a fully closed conjugated planar COF system, leading to the formation of the TiCOF anchored with ordered N-coordinated Ti-metal centres. $\mathrm{Cu}-\mathrm{COF}$ and $\mathrm{Co}-\mathrm{COF}$ were prepared through the same method, but $\mathrm{TiCl}_{4}$ was replaced by $1 \mathrm{mmol}$ $\mathrm{CuCl}_{2} \cdot 2 \mathrm{H}_{2} \mathrm{O}$ and $1 \mathrm{mmol} \mathrm{CoCl} \cdot 6 \mathrm{H}_{2} \mathrm{O}$, respectively.

Material characterizations. XRD analysis was carried out on a powder X-ray diffractometer (Bruker D8 Advance) with a $\mathrm{Cu} \mathrm{K \alpha}(\lambda=1.5406 \AA)$ radiation source from 
10 and $90^{\circ}$ at a scanning rate of $2^{\circ} \mathrm{min}^{-1}$. SEM (FEI Nova NanoSEM 450) and TEM (JEM-2100) were used for the surface morphology and structural characterizations. Elemental mappings were performed by an energy-dispersive X-ray spectroscopy (EDX, Bruker Quantax-100) accessory attached on the SEM instrument. The surface element compositions and detailed valence states of all samples were determined by XPS via a PHI-5000 Versa Probe instrument. Raman spectra were collected with a Horiba JY Evolution spectrometer using a $633 \mathrm{~nm}$ laser source. The accurate weight loadings of metal centres in all samples were determined by ICP-OES (Optima 5300DV) by dissolving the as-prepared catalysts in a mixture of concentrated hydrochloric and nitric acids $\left(\mathrm{V}_{\mathrm{HCl}}: \mathrm{V}_{\mathrm{HNO}}=3: 1\right)$. Briefly, $2 \mathrm{mg}$ of the specific sample was dissolved in $12 \mathrm{~mL}$ aqua regia $\left(\mathrm{V}(\mathrm{HCl}): \mathrm{V}\left(\mathrm{HNO}_{3}\right)=3: 1\right)$ by water-bath heating. Then, the solution was transferred to a volumetric flask and diluted with water to $100 \mathrm{~mL}$. Subsequently, the corresponding metal concentration of the solution was determined by ICP-OES. Finally, the mass of corresponding metal in the catalyst can be calculated according to the obtain metal concentration and solution volume. UV-Vis absorption spectra were measured on a Shimadzu UV-2600 spectrophotometer. Ion chromatography data were obtained on a Dionex ICS 900 instrument.

Electrochemical measurements. Electrochemical measurements were carried out with a standard three-electrode system. Pt disk and $\mathrm{Ag} / \mathrm{AgCl}$ electrodes were used as the reference and counter electrodes, respectively. A piece of $\mathrm{CP}\left(1 \times 1 \mathrm{~cm}^{2}\right)$ coated with the electrocatalyst (areal loading: $0.4 \mathrm{mg} \cdot \mathrm{cm}^{-2}$ ) was used as the working electrode. The working electrode was prepared as follows: $5 \mathrm{mg}$ of electrocatalyst was dispersed into a mixture containing $950 \mu \mathrm{L}$ of ethanol and $50 \mu \mathrm{L}$ of a $5 \mathrm{wt} \%$ Nafion solution, followed by an ultrasonic treatment for 60 min to form a homogeneous electrocatalyst ink. Then, $80 \mu \mathrm{L}$ of electrocatalyst ink was coated onto the $\mathrm{CP}$ and dried at $60{ }^{\circ} \mathrm{C}$ under vacuum before use. The NRR tests were performed at room temperature $\left(25^{\circ} \mathrm{C}\right)$ in a twocompartment electrochemical cell separated by a Nafion 117 proton exchange membrane. Before the NRR tests, the proton exchange membrane was successively treated in a $\mathrm{H}_{2} \mathrm{O}_{2}(5 \%)$ aqueous solution at $80{ }^{\circ} \mathrm{C}$ for $1 \mathrm{~h}$, ultrapure deionized water and 
$0.5 \mathrm{M} \mathrm{H}_{2} \mathrm{SO}_{4}$, respectively. High-purity $\mathrm{N}_{2}$ was continuously flowed into the cathode compartment during the NRR process. All potentials in this work were calibrated to RHE using the equation:

$$
\mathrm{E}(\text { vs. RHE })=\mathrm{E}(\text { vs. } \mathrm{Ag} / \mathrm{AgCl})+0.1989+0.059 \times \mathrm{pH}
$$

Determination of ammonia. The yielded ammonia was spectrophotometrically detected by the standard indophenol blue indicator method. Typically, $2 \mathrm{~mL}$ of the electrolyte was collected from the cathode compartment after the chronoamperometry process, followed by the addition of $2 \mathrm{~mL}$ of $1 \mathrm{M}$ aqueous $\mathrm{NaOH}$ solution containing $5 \%$ salicylic acid and $5 \%$ sodium citrate. Then, $1 \mathrm{~mL}$ of $0.05 \mathrm{M} \mathrm{NaClO}$ and $0.2 \mathrm{~mL}$ of $1 \% \mathrm{C}_{5} \mathrm{FeN}_{6} \mathrm{Na}_{2} \mathrm{O} \cdot 2 \mathrm{H}_{2} \mathrm{O}$ were successively added into the above solution. After standing in the dark for $2 \mathrm{~h}$, the concentration of indophenol blue was measured using an UVVis spectrophotometer at the wavelength of $655 \mathrm{~nm}$. The light absorbance curve was calibrated in a $0.05 \mathrm{M} \mathrm{HCl}$ solution using standard $\mathrm{NH}_{4} \mathrm{Cl}$ solutions with different concentrations. For the preparation of $\mathrm{NH}_{3}$ standard solution $\left(1000 \mu \mathrm{g} \cdot \mathrm{mL}^{-1}\right), 0.3148 \mathrm{~g}$ of pre-dried $\mathrm{NH}_{4} \mathrm{Cl}\left(105{ }^{\circ} \mathrm{C}\right.$ for $\left.2 \mathrm{~h}\right)$ was dissolved into a $0.05 \mathrm{M} \mathrm{HCl}$ solution and diluted to $100 \mathrm{~mL}$. For the preparation of diluted $\mathrm{NH}_{3}$ standard solution $\left(10 \mu \mathrm{g} \cdot \mathrm{mL}^{-1}\right)$, $1 \mathrm{~mL}$ of $\mathrm{NH}_{3}$ standard solution $\left(1000 \mu \mathrm{g} \cdot \mathrm{mL}^{-1}\right)$ was dispersed into a $0.05 \mathrm{M} \mathrm{HCl}$ solution and diluted to $100 \mathrm{~mL}$. For the preparation of further diluted $\mathrm{NH}_{3}$ standard solutions $\left(0.05,0.1,0.2,0.3,0.4,0.5,0.6,0.8\right.$ and $\left.1.0 \mu \mathrm{g} \cdot \mathrm{mL}^{-1}\right), 10,20,40,60,80,100$, 120,160 and $200 \mu \mathrm{L}$ of a $10 \mu \mathrm{g} \cdot \mathrm{mL}^{-1} \mathrm{NH}_{3}$ standard solution was added into a PTFE tube and diluted to $2 \mathrm{~mL}$ with a $0.05 \mathrm{M} \mathrm{HCl}$ solution, respectively.

The principle of the indophenol indicator method to measuring ammonia concentration, as follows:

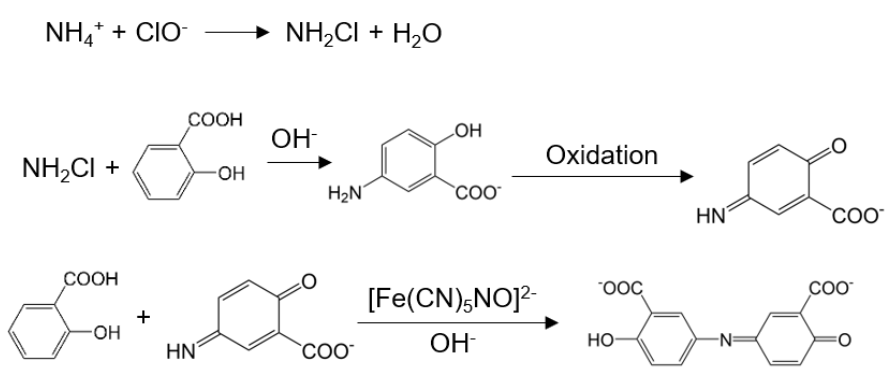


where the first step is the reaction between ammonium ions and sodium hypochlorite to forming chloramines. The second step is the chloramines and salicylic acid reacts under an alkaline environment to form an intermediate product (5-amino salicylic acid), and then rapidly oxidize to 2 carboxy-1, 4 quinonimine. Finally, 2 carboxy-1, 4 quinonimine and salicylic acid reacts to form blue-green indophenol. In the range of $0.01 \sim 0.5 \mathrm{mg}$ (Ammonia-N)/L, the content of indophenol are proportional to the light absorbance at $655 \mathrm{~nm}$ wavelength was measured by UV-Vis spectrophotometer.

Determination of hydrazine. The possible $\mathrm{N}_{2} \mathrm{H}_{4}$ by-product in the electrolytes was determined by the Watt and Chrisp method. Briefly, para-(dimethylamino) benzaldehyde $(5.99 \mathrm{~g})$, hydrochloric acid $(30 \mathrm{~mL})$ and ethanol $(300 \mathrm{~mL})$ were mixed and used as a sensitive chromogenic reagent. Then, $2 \mathrm{~mL}$ of electrolyte was collected from the cathode compartment and mixed with $5 \mathrm{~mL}$ of the chromogenic reagent at room temperature. After standing for $20 \mathrm{~min}$ at room temperature, the light absorbance of the resulting solution was measured using a UV-Vis spectrophotometer at the wavelength of $457 \mathrm{~nm}$.

\section{Calculations of $\mathrm{NH}_{3}$ yield rate and Faradaic efficiency.}

The $\mathrm{NH}_{3}$ yield rate $\left(\mathrm{R}_{\mathrm{NH} 3}\right)$ was calculated by the following equation:

$$
\mathrm{R}_{\mathrm{NH} 3}\left(\mu \mathrm{g} \cdot \mathrm{h}^{-1} \mathrm{mg}^{-1} \text { cat. }\right)=\left(\mathrm{C}_{\mathrm{NH} 3} \times \mathrm{V}\right) /\left(\mathrm{t} \times \mathrm{m}_{\text {cat. }}\right)
$$

where $\mathrm{C}_{\mathrm{NH}}\left(\mu \mathrm{g} \cdot \mathrm{mL}^{-1}\right)$ is the measured $\mathrm{NH}_{3}$ concentration, $\mathrm{V}(\mathrm{mL})$ is the volume of the electrolyte, $\mathrm{t}(\mathrm{h})$ is the reaction time, and $\mathrm{m}(\mathrm{mg})$ is the catalyst loading on the CP.

The Faradaic efficiency (FE) was calculated by the following equation:

$$
\mathrm{FE}=\left(3 \times \mathrm{F} \times \mathrm{C}_{\mathrm{NH} 3} \times \mathrm{V}\right) /(17 \times \mathrm{Q})
$$

where $\mathrm{F}$ is the Faraday constant $\left(96485 \mathrm{C} \mathrm{mol}^{-1}\right)$ and Q (C) is the total quantity of applied electricity. 
${ }^{15} \mathrm{~N}$ Isotope Labelling Experiments. The ${ }^{15} \mathrm{~N}$ isotope labelling experiments were performed by using ${ }^{15} \mathrm{~N}_{2}$ feeding gas (98 atom $\%{ }^{15} \mathrm{~N}$, Aldrich) to clarify the source of ammonia. To prepare the NMR sample, $10 \mathrm{~mL}$ of electrolyte after the long-term NRR at $-0.2 \mathrm{~V}$ (vs. RHE) for $12 \mathrm{~h}$ in a $0.05 \mathrm{M} \mathrm{HCl}$ solution was concentrated to $\sim 1 \mathrm{~mL}$ via reduced pressure evaporation. Then, $550 \mu \mathrm{L}$ of the concentrated solution was put into a NMR tube, and a closed tube with a higher liquid level of $\mathrm{D}_{2} \mathrm{O}$ was also added as a calibration sample for ${ }^{1} \mathrm{H}$ NMR analysis. The one-dimensional ${ }^{1} \mathrm{H}$ NMR spectra were collected by a superconducting Fourier transform NMR spectrometer (Bruker Avance$600)$ with the necessary suppression of water peaks by water pre-saturation method. The ${ }^{1} \mathrm{H}$ spectrum splitting of ${ }^{14} \mathrm{NH}_{4}{ }^{+}$and ${ }^{15} \mathrm{NH}_{4}{ }^{+}$meets $2 \mathrm{nl}+1$ rules, where $\mathrm{n}$ is the number of core caused by splitting, 1 is the spin quantum number of core caused by splitting. In the case of ${ }^{14} \mathrm{NH}_{4}{ }^{+}, 1=1, \mathrm{n}=1$, so the number of ${ }^{1} \mathrm{H}$ spectrum splitting is $2 \times 1 \times 1+1=3$. Similarly, for ${ }^{15} \mathrm{NH}_{4}{ }^{+}, 1=1 / 2, \mathrm{n}=1$, the number of ${ }^{1} \mathrm{H}$ spectrum splitting is $2 \times 1 \times 1 / 2+1=2$.

DFT Calculations. DFT calculations were performed by using the Vienna ab initio Simulation Package (VASP). The exchange correlation interaction was described by generalized gradient approximation (GGA) with the Perdew Burke Ernzerhof (PBE) functional. An energy cut-off of $450 \mathrm{eV}$ was used and a k-point sampling set of $2 \times 2 \times 1$ was tested to be converged. A force tolerance of $0.02 \mathrm{eV} \AA^{-1}$, energy tolerance of $1.0 \times 10^{-5} \mathrm{eV}$ per atom were considered. The vacuum space along the $\mathrm{z}$ direction is set to be $20 \AA$.

The adsorption energy $(\Delta \mathrm{E})$ of $\mathrm{A}$ group adsorbed on the surface was defined as:

$$
\Delta \mathrm{E}=\mathrm{E} * \mathrm{~A}-\left(\mathrm{E} *+\mathrm{E}_{\mathrm{A}}\right)
$$

where $* A$ and $*$ denote the adsorption of A group on substrates and the bare substrates, 
respectively. $\mathrm{E}_{\mathrm{A}}$ denotes the energy of A group. Here, A group includes $\mathrm{N}_{2}$ and reaction intermediates produced by HER and NRR.

The Gibbs free energy $(\mathrm{G})$ of the intermediates was calculated by using the computational hydrogen electrode (CHE) model proposed by Nørskov. The Gibbs free energy change $(\Delta G)$ of each chemical reaction was calculated by:

$$
\Delta \mathrm{G}=\Delta \mathrm{E}_{\mathrm{DFT}}+\Delta \mathrm{ZPE}-\mathrm{T} \Delta \mathrm{S}+\Delta \mathrm{GU}+\Delta \mathrm{GPH}
$$

where EDFT, ZPE, T, and S denote the total energy calculated by DFT, zero point energy, temperature, and entropy, respectively. $\Delta \mathrm{GU}=-\mathrm{eU}(\mathrm{U}$ is the potential measured against $\mathrm{NHE})$ and $\Delta \mathrm{GpH}=-\mathrm{kBT} \ln (10) \times \mathrm{pH}$. Here, $\mathrm{T}=298.15 \mathrm{~K}$ and $\mathrm{PH}=0$ are considered.

The d-band centre $\left(\varepsilon_{\mathrm{d}}\right)$ of $\mathrm{M}-\mathrm{COF}(\mathrm{M}=\mathrm{Ti}, \mathrm{Cu}$ or $\mathrm{Co})$ was calculated as follows:

$$
\varepsilon_{d}=\frac{\int_{-\infty}^{+\infty} \varepsilon \rho_{d} d \varepsilon}{\int_{-\infty}^{+\infty} \rho_{d} d \varepsilon}
$$

where $\rho_{d}$ is the density of states projected onto the d orbital of metal atom, $\varepsilon$ is the energy width of the d orbital. 


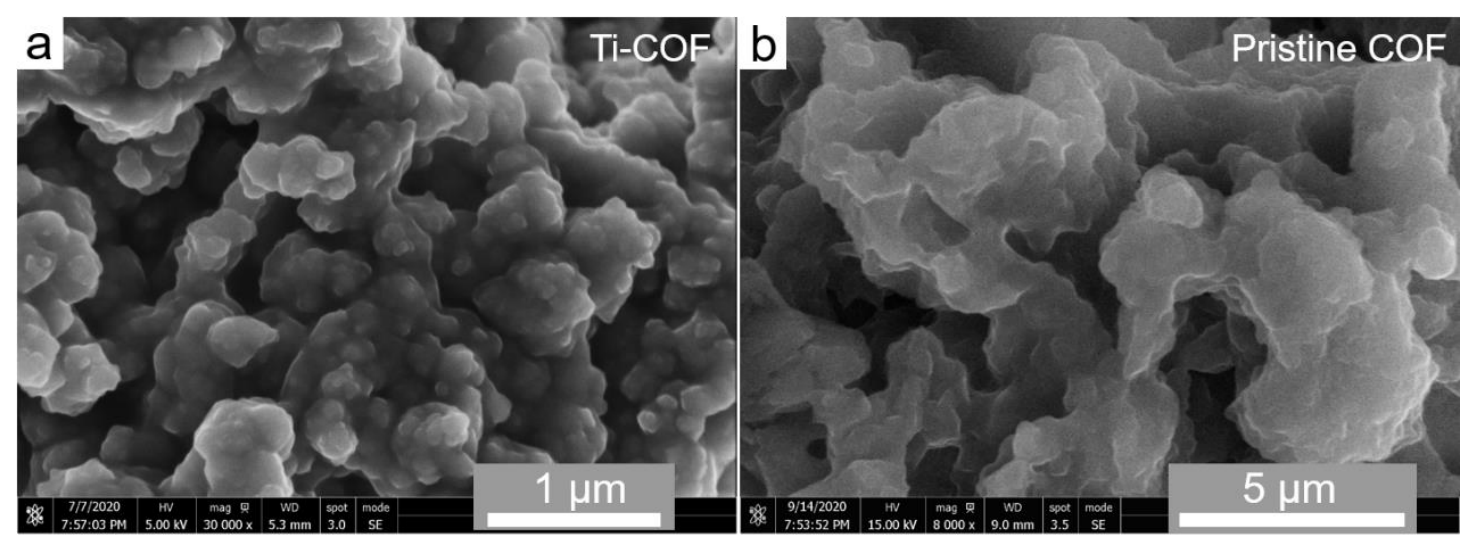

Figure S1. SEM images of (a) Ti-COF and (b) pristine COF samples. 


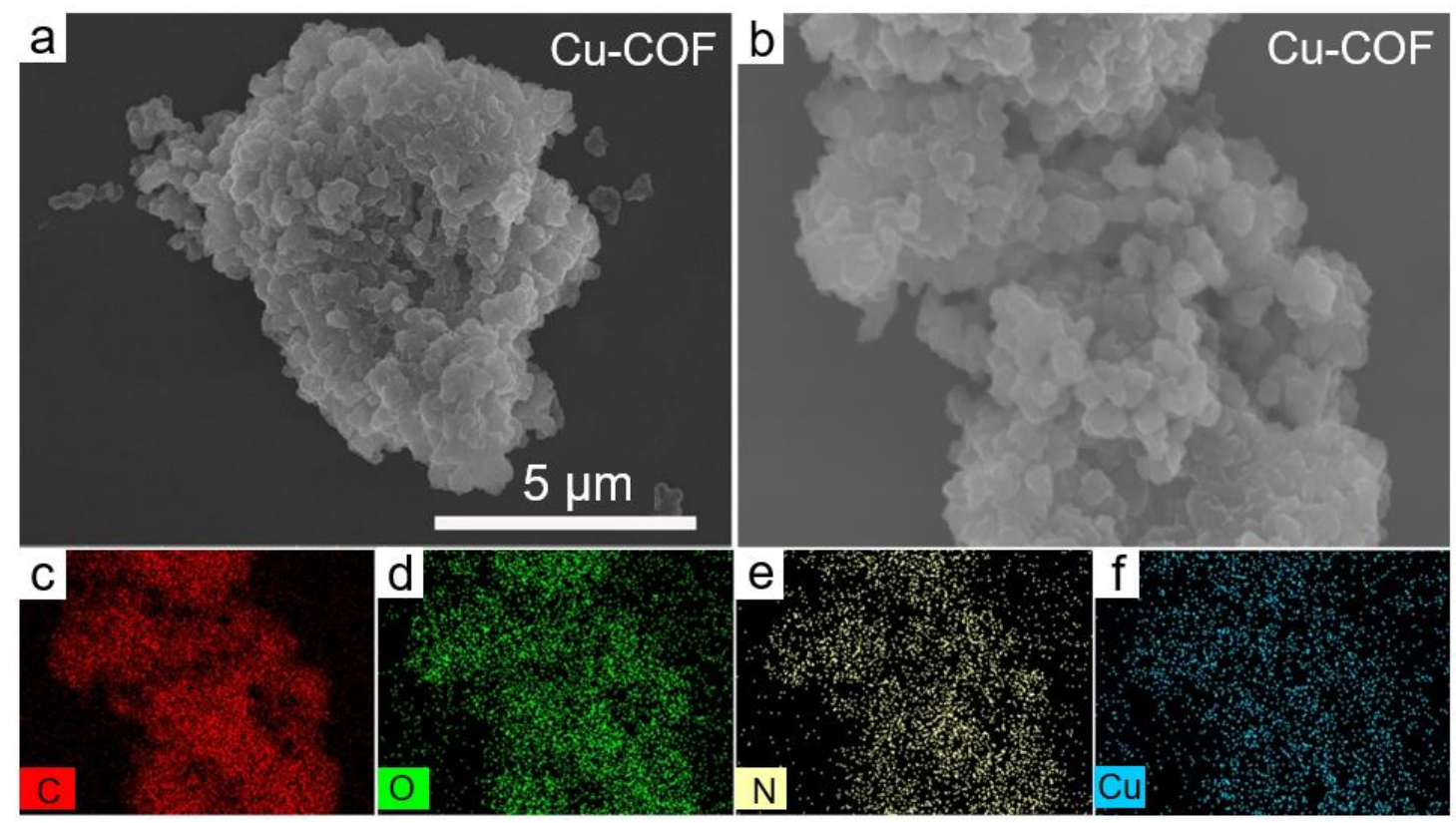

Figure S2. (a, b) SEM and (c-f) elemental mapping images of $\mathrm{Cu}-\mathrm{COF}$. 


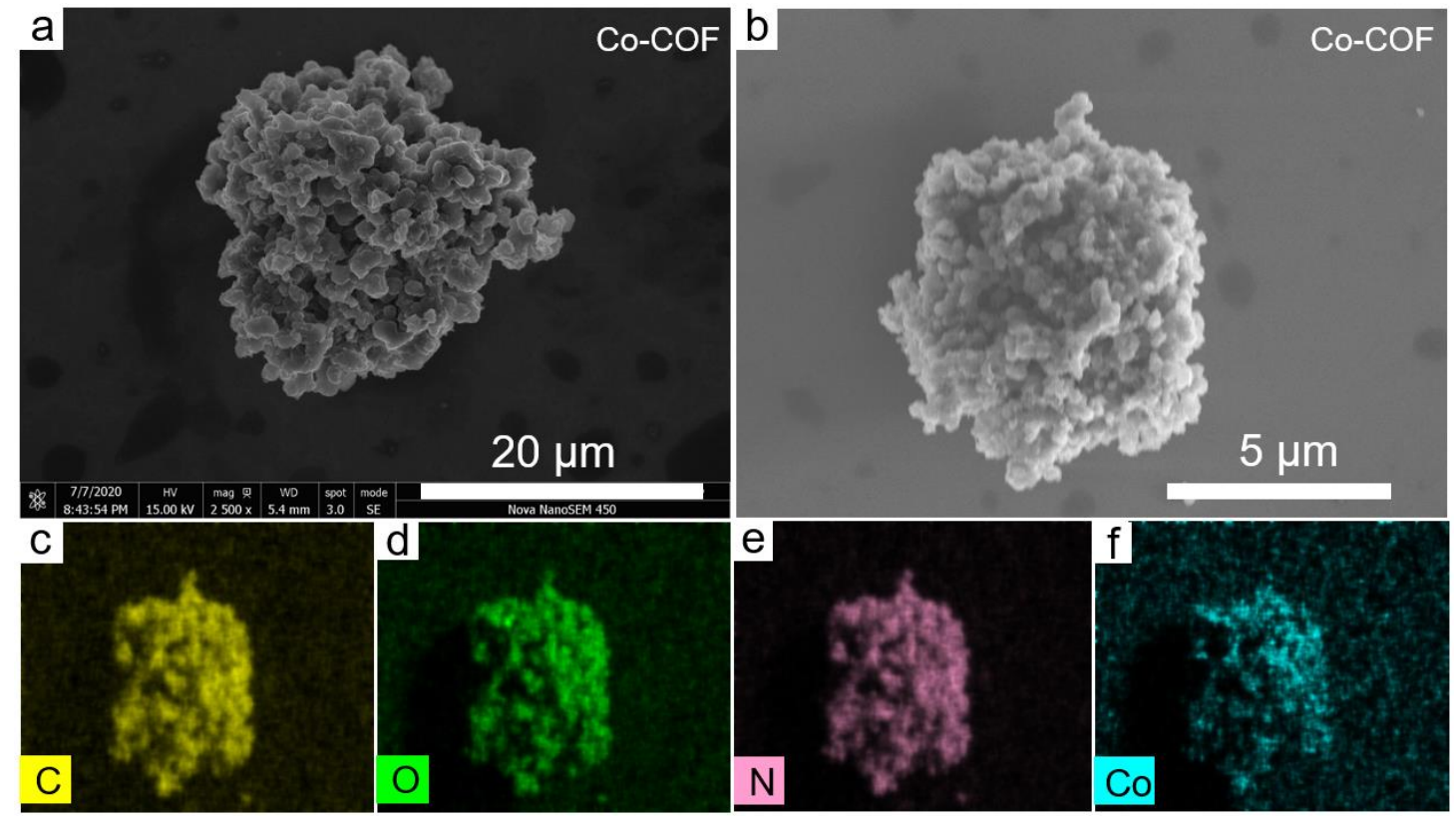

Figure S3. (a, b) SEM and (c-f) elemental mapping images of Co-COF. 


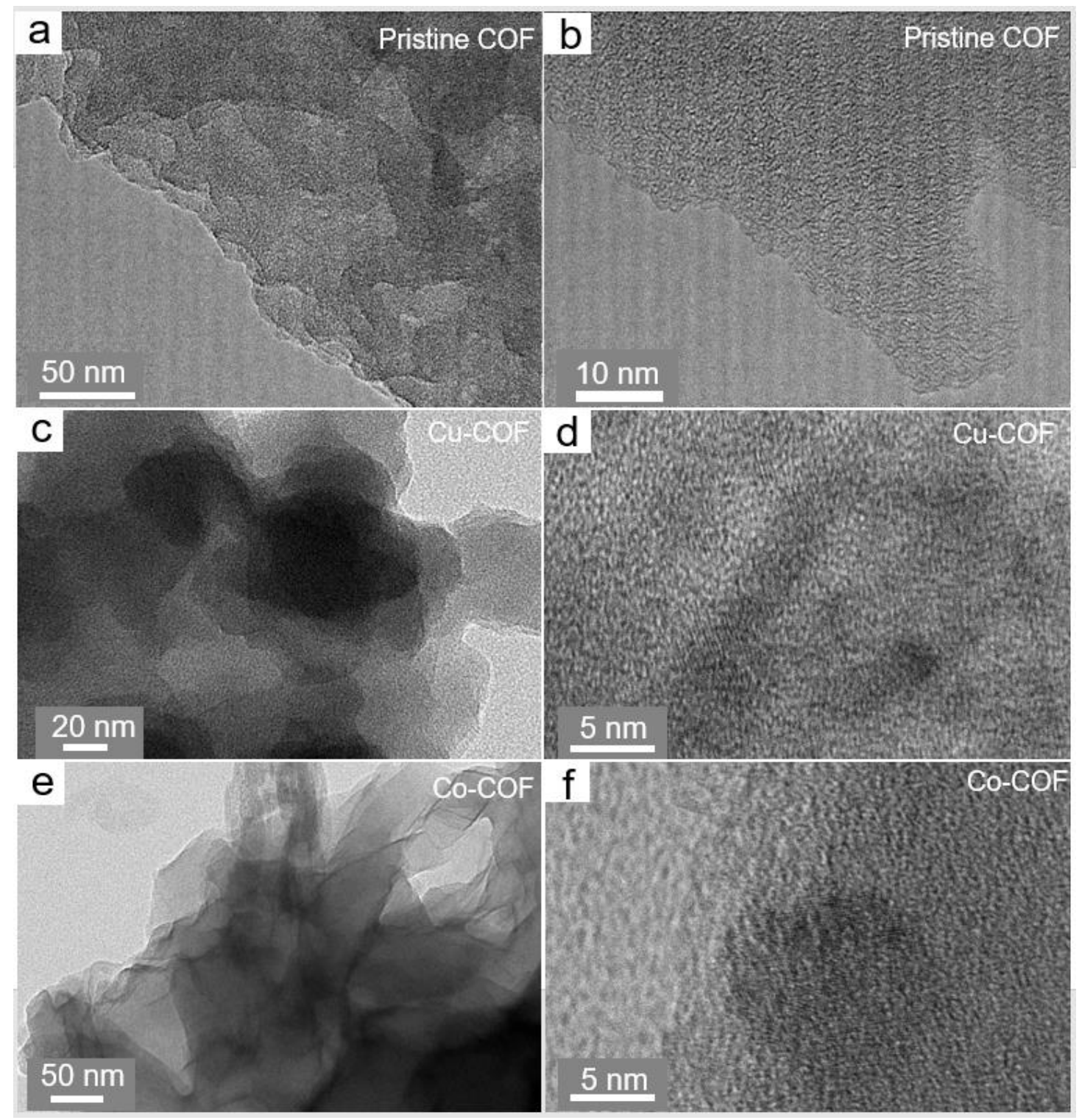

Figure S4. TEM and HRTEM images of $(a, b)$ pristine COF, $(c, d) \mathrm{Cu}-\mathrm{COF}$ and $(e, f)$ Co-COF samples. 


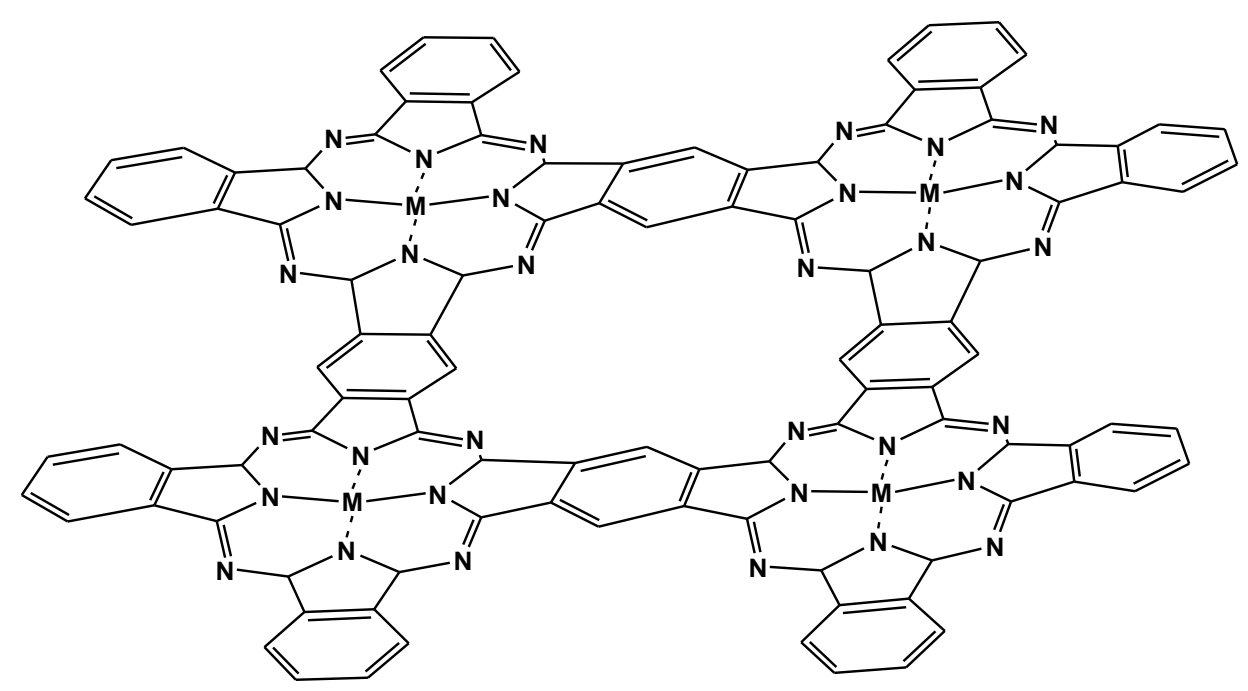

Figure S5. Simulated atomic structures of $\mathrm{M}-\mathrm{COF}(\mathrm{M}=\mathrm{Ti}, \mathrm{Cu}$ or $\mathrm{Co})$. 

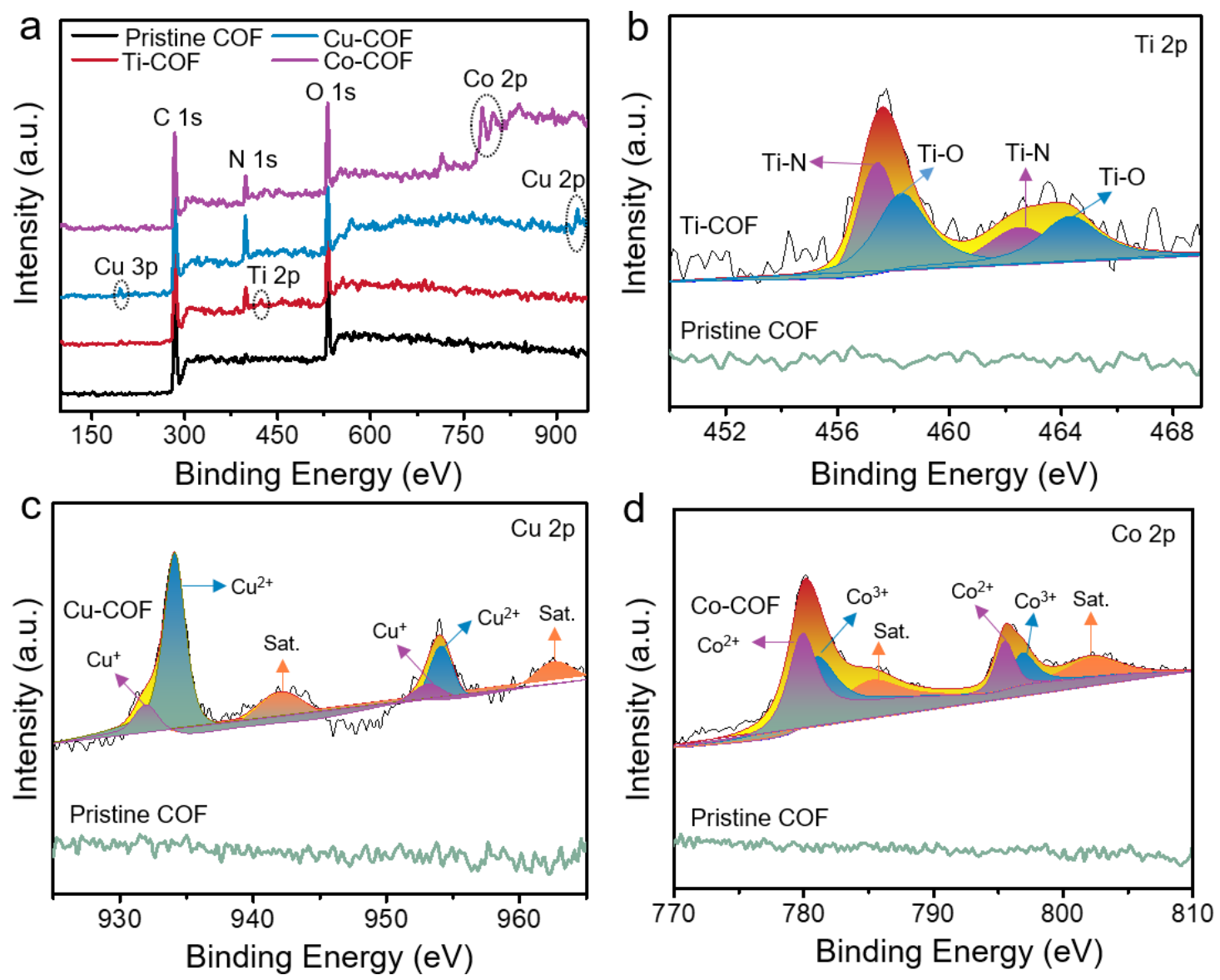

Figure S6. (a) Survey XPS spectra of pristine COF, Ti-COF, Cu-COF and Co-COF. (b) High-resolution XPS spectra at Ti 2P region of pristine COF and Ti-COF. (c) Highresolution XPS spectra at $\mathrm{Cu} 2 \mathrm{P}$ region of pristine COF and $\mathrm{Cu}-\mathrm{COF}$. (d) Highresolution XPS spectra of Co $2 \mathrm{P}$ region of pristine COF and Co-COF.

The survey spectra of pristine $\mathrm{COF}$, Ti-COF, $\mathrm{Cu}-\mathrm{COF}$ and $\mathrm{Co}-\mathrm{COF}$ catalysts are presented in Figure S6a, and the characteristic signals from C 1s, N 1s and O1s regions can be clearly observed in all samples. Moreover, for Ti-COF, $\mathrm{Cu}-\mathrm{COF}$ and $\mathrm{Co}-\mathrm{COF}$, the presence of metal centres $(\mathrm{Ti}, \mathrm{Cu}$ or $\mathrm{Co})$ in the corresponding $\mathrm{COF}$ frameworks is confirmed by comparing with the high-resolution XPS spectra of pristine COF (Figure S6b-S6d). These analysis results further confirm that $\mathrm{Ti}, \mathrm{Cu}$ or $\mathrm{Co}$ metal centres are successfully incorporated into the corresponding COF frameworks. 


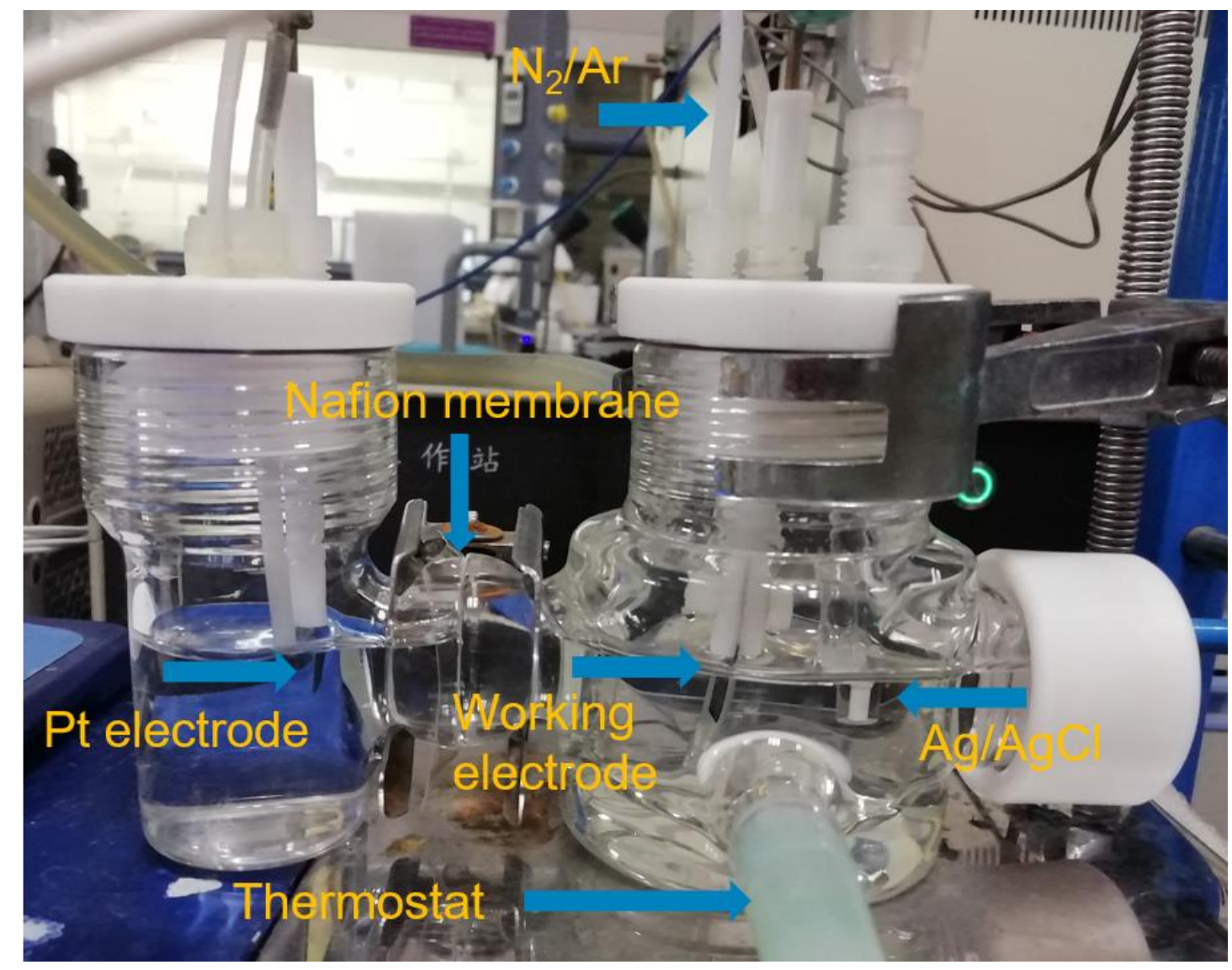

Figure S7. Optical photograph of the electrochemical NRR apparatus setup with two compartments separated by a proton exchange membrane.

$\mathrm{N}_{2}$ was continually flowed into the cathodic compartment at a constant flow rate of $20 \mathrm{~mL} \mathrm{~min}^{-1}$ during the NRR process. 


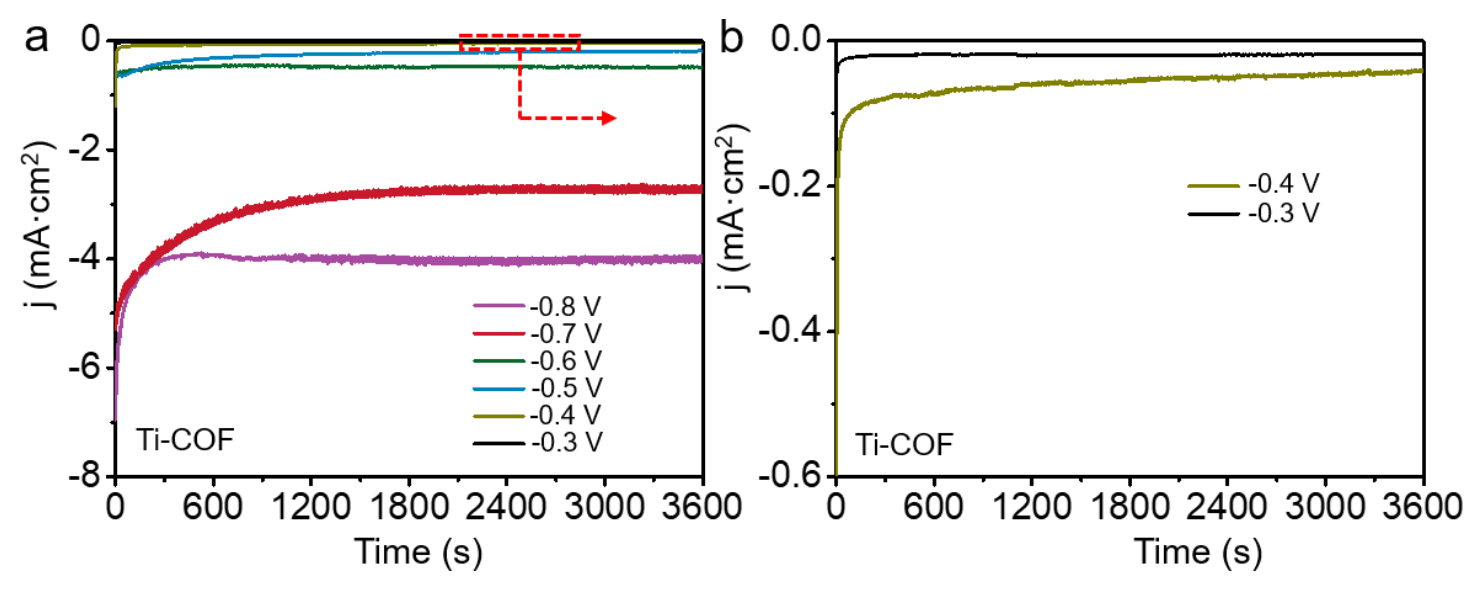

Figure S8. (a, b) I-t curves of Ti-COF under different applied potentials. 

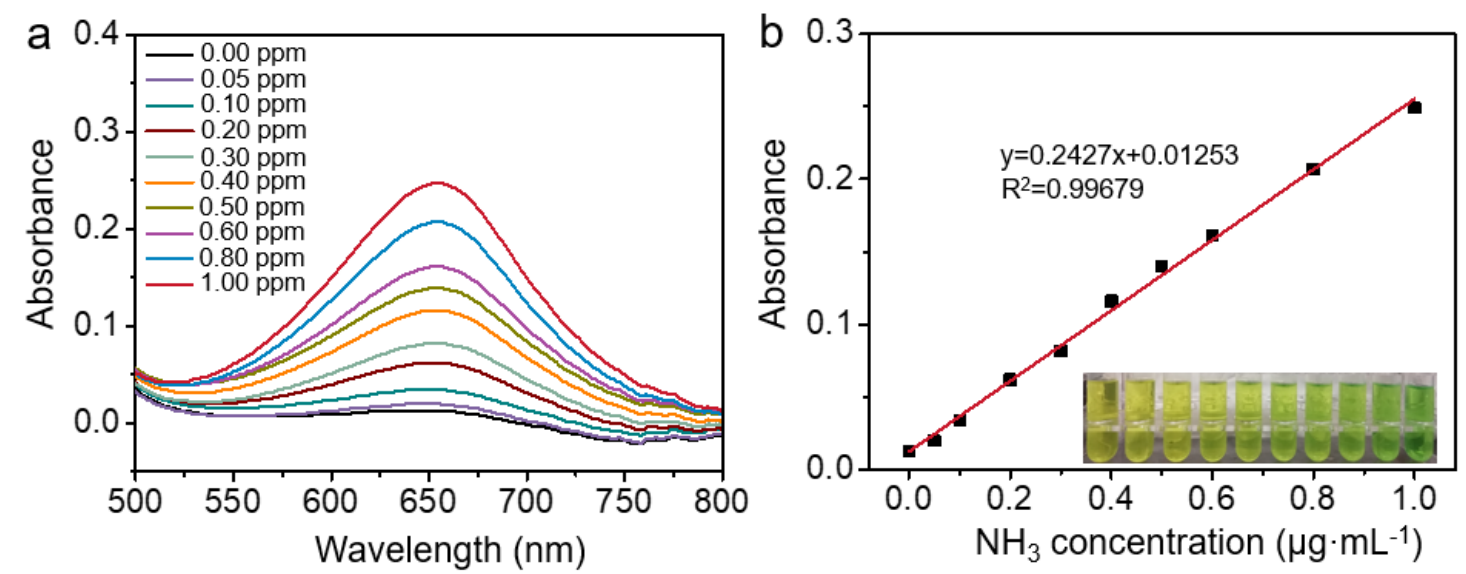

Figure S9. (a) UV-Vis absorption spectra of $\mathrm{NH}_{3}$ standard solution with different concentrations. (b) Calibration curve used for the calculation of $\mathrm{NH}_{3}$ concentrations. The light absorbance at $655 \mathrm{~nm}$ wavelength was measured by UV-Vis spectrophotometer.

Figure S9 indicate a good linear relationship of the light absorbance at $665 \mathrm{~nm}$ wavelength with the ammonia concentration. 

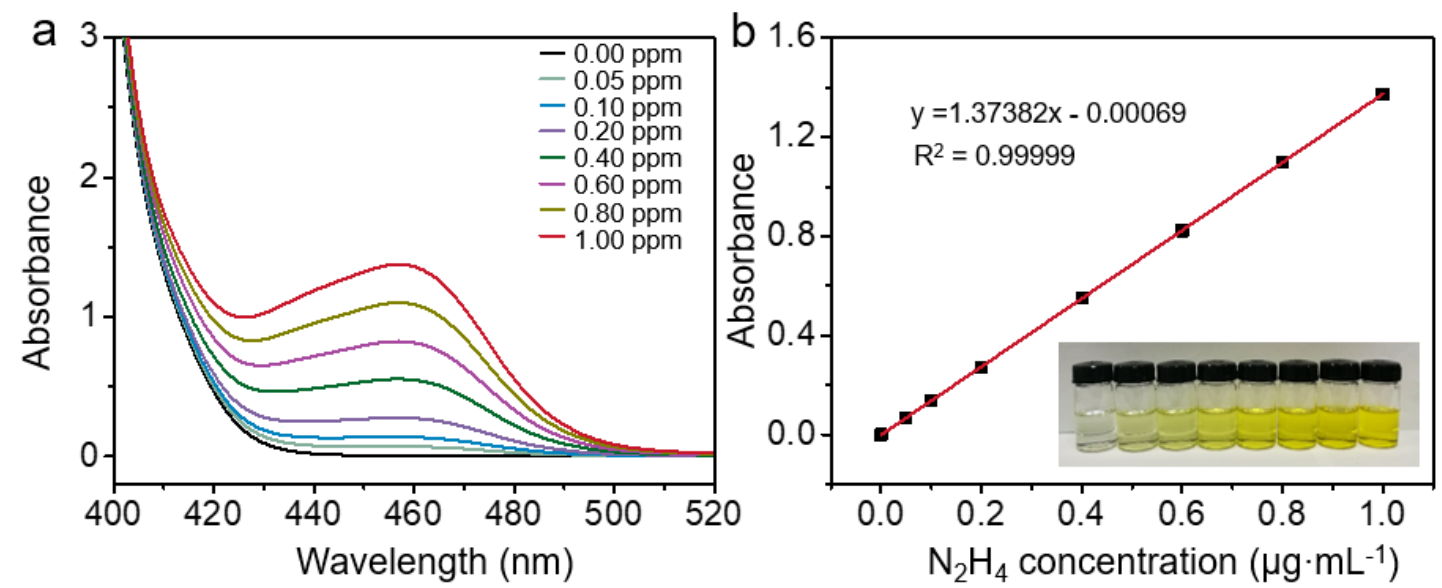

Figure S10. (a) UV-Vis absorption spectra of $\mathrm{N}_{2} \mathrm{H}_{4}$ standard solutions with different concentrations. (b) Calibration curve used for the calculation of $\mathrm{N}_{2} \mathrm{H}_{4}$ concentrations. The light absorbance at $457 \mathrm{~nm}$ wavelength was measured by UV-vis spectrophotometer. 


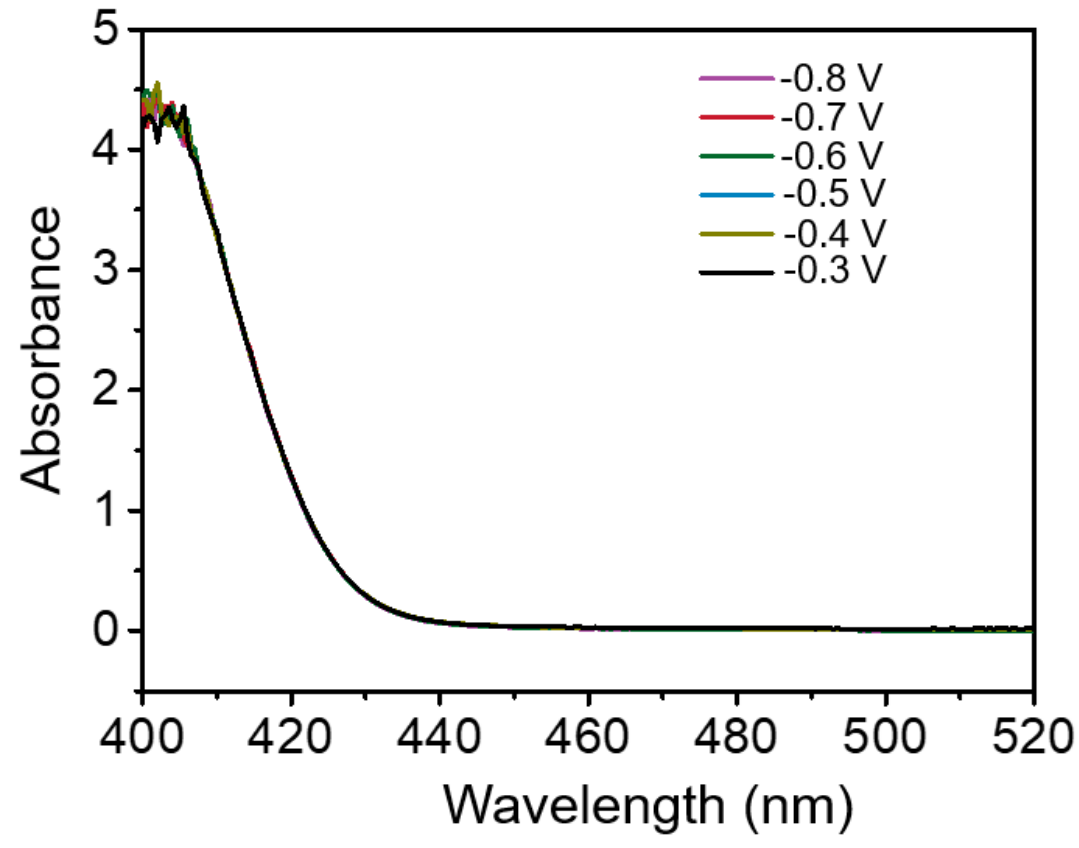

Figure S11. UV-Vis absorption spectra of the $\mathrm{N}_{2}$-saturated $0.05 \mathrm{M} \mathrm{HCl}$ solution containing para-dimethylamino-benzaldehyde indicator after the NRR test of Ti-COF for $1 \mathrm{~h}$ at various applied potentials. 

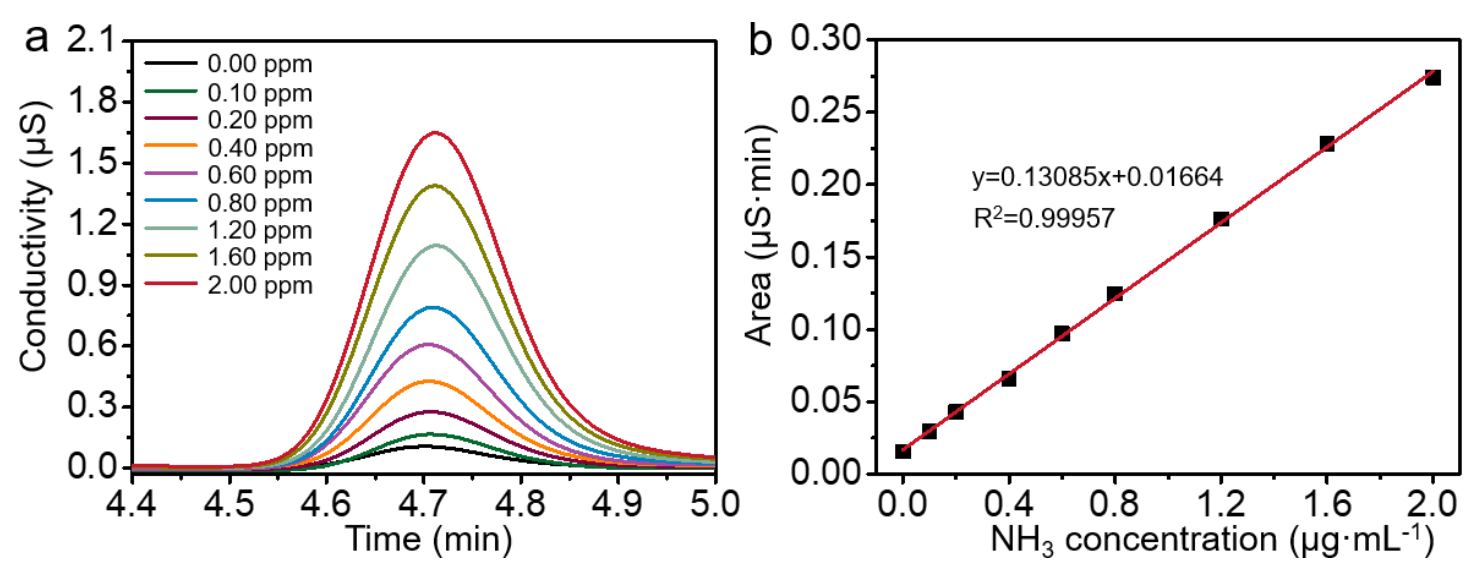

Figure S12. (a) Ion chromatogram analysis of the $\mathrm{NH}_{3}$ standard solutions with different concentrations. (b) Calibration curve used for the calculation of $\mathrm{NH}_{3}$ concentrations. 

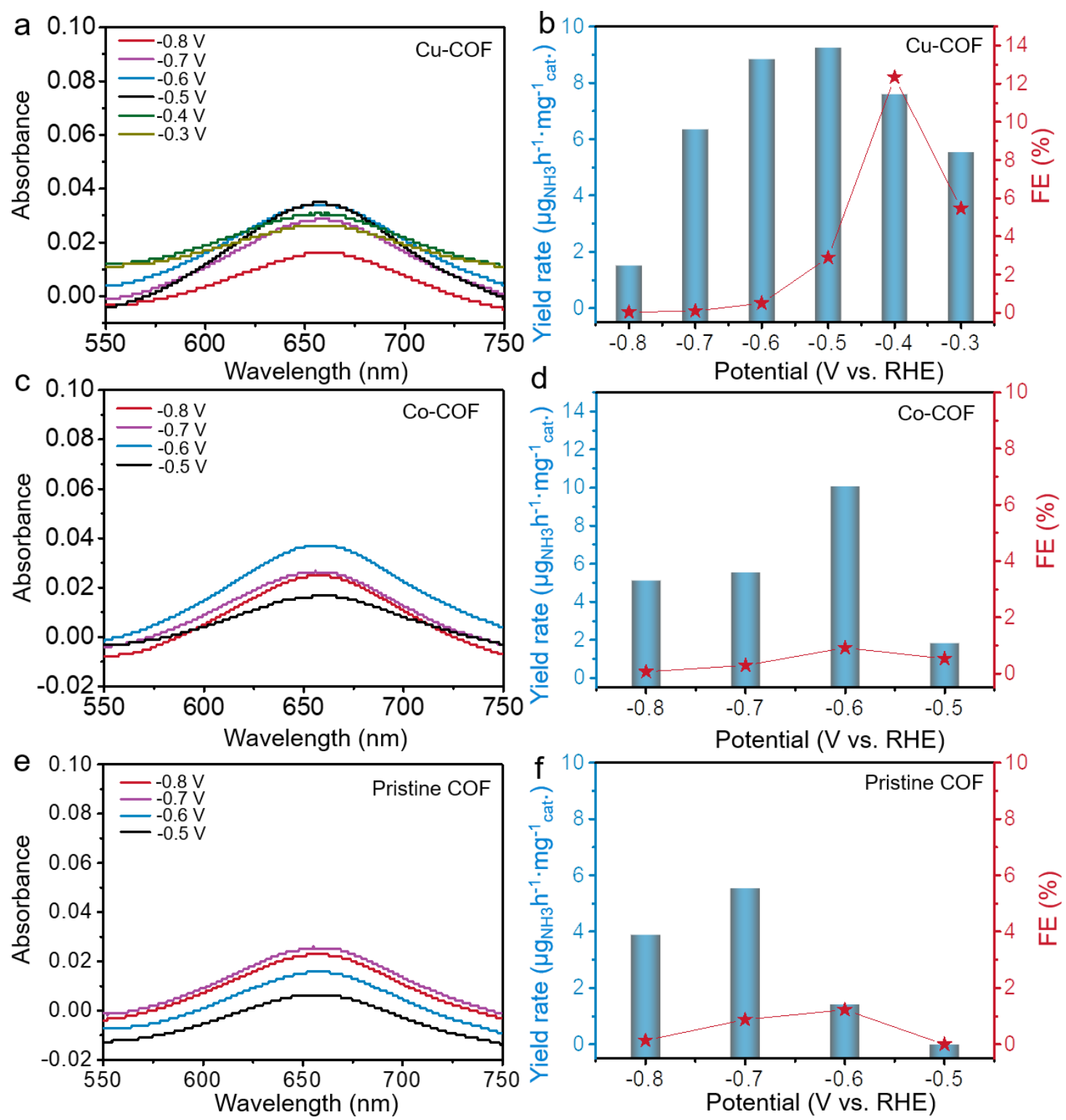

Figure S13. (a, c, e) UV-Vis absorption spectra of the product solution colored with indophenol indicator after the NRR test for $1 \mathrm{~h}$ and $(\mathrm{b}, \mathrm{d}, \mathrm{f})$ the calculated $\mathrm{NH}_{3}$ yield rates and corresponding FE values of $(\mathrm{a}, \mathrm{b}) \mathrm{Cu}-\mathrm{COF},(\mathrm{c}, \mathrm{d}) \mathrm{Co}-\mathrm{COF}$ and $(\mathrm{e}, \mathrm{f})$ pristine $\mathrm{COF}$ at given potentials in $\mathrm{N}_{2}$-saturated $0.05 \mathrm{M} \mathrm{HCl}$ electrolytes. 

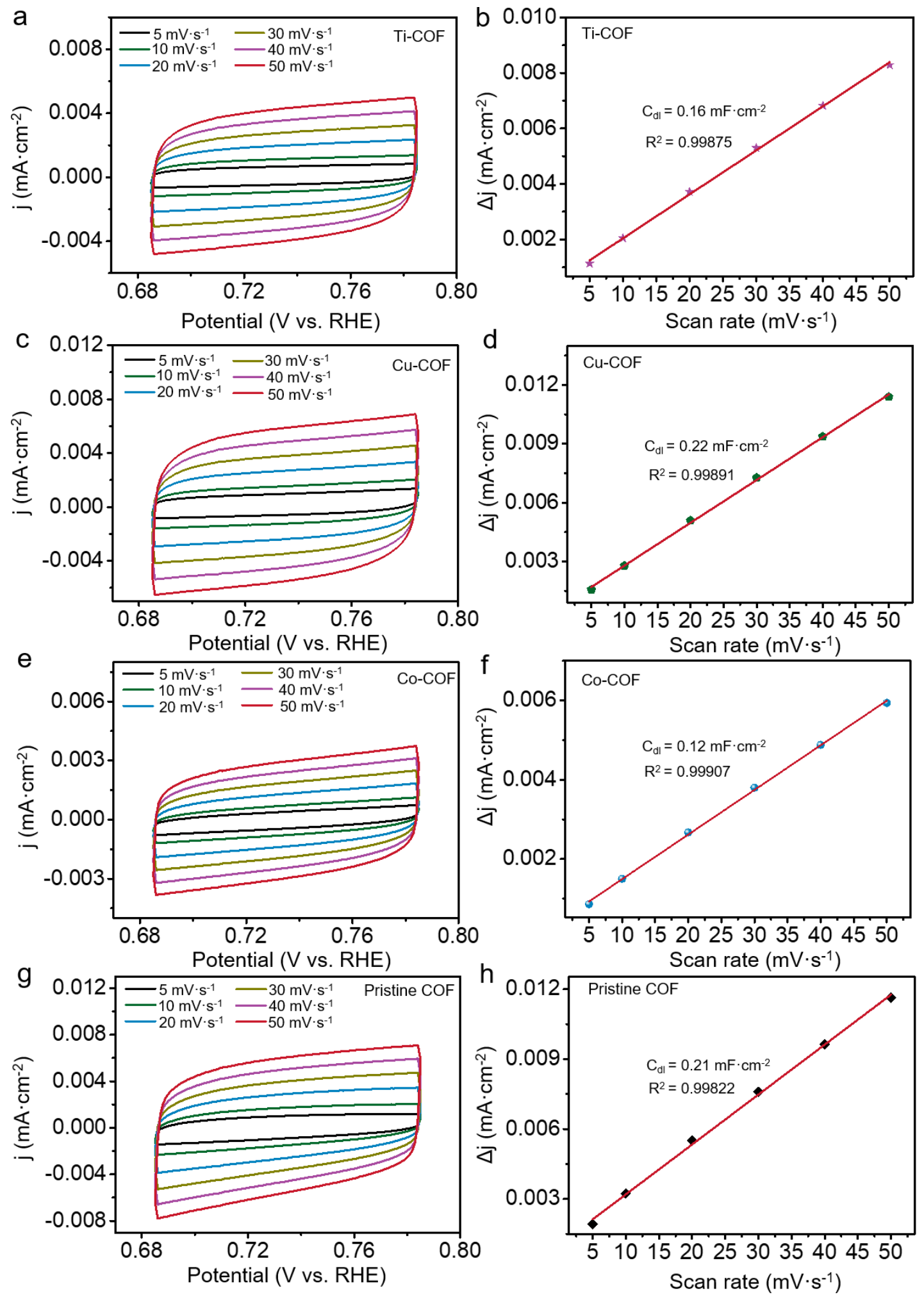

Figure S14. CV curves measured at different scan rates and corresponding plots of the double-layer capacitances $\left(\mathrm{C}_{\mathrm{dl}}\right)$ for $(\mathrm{a}, \mathrm{b}) \mathrm{Ti}-\mathrm{COF},(\mathrm{c}, \mathrm{d}) \mathrm{Cu}-\mathrm{COF},(\mathrm{e}, \mathrm{f}) \mathrm{Co}-\mathrm{COF}$ and $(\mathrm{g}$, h) pristine COF catalysts. 
As shown in Figure S14, CV curves at different scan rates were obtained in the range of non-Faradaic current potential. The $\mathrm{C}_{\mathrm{dl}}$ values of all catalysts were calculated by linearly plotting the corresponding anodic charging current against the scan rate at the open-circuit potential. The $\mathrm{C}_{\mathrm{dl}}$ values of Ti-COF, $\mathrm{Cu}-\mathrm{COF}, \mathrm{Co}-\mathrm{COF}$ and pristine $\mathrm{COF}$ stay at a comparable level. Since the electrochemically active surface area (ECSA) is proportional to $\mathrm{C}_{\mathrm{dl}}$, the above $\mathrm{C}_{\mathrm{dl}}$ values suggest that the introduction of transition metal centres $(\mathrm{Ti}, \mathrm{Cu}$ and $\mathrm{Co})$ into the $\mathrm{COF}$ framework does not contribute to increasing the ECSA. 


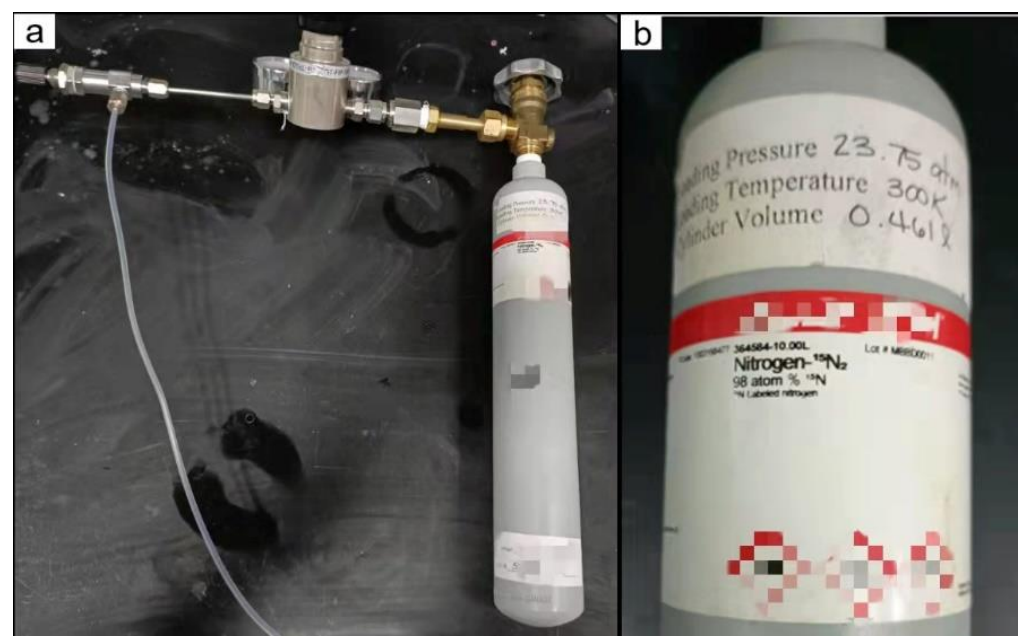

Figure S15. Optical photograph of the apparatus for the continuous bubbling of ${ }^{15} \mathrm{~N}_{2}$ feeding gas $\left(98 \%\right.$ enrichment of $\left.{ }^{15} \mathrm{~N}\right)$. 

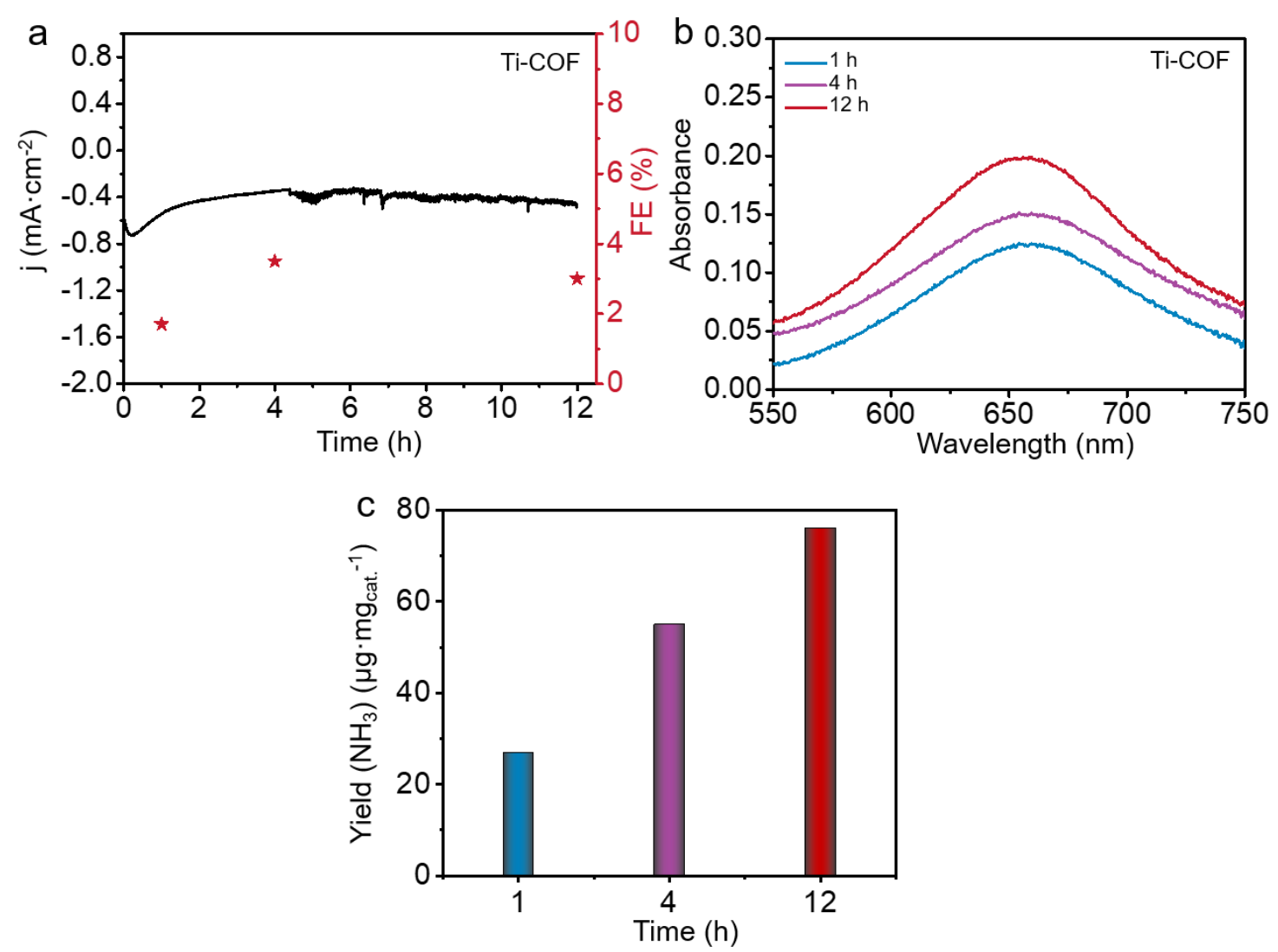

Figure S16. (a) Long-term stability test of Ti-COF catalyst for the NRR at -0.7 V. (b) UV-Vis absorption spectra of the electrolyte after the NRR test of Ti-COF at a potential of $-0.7 \mathrm{~V}$ for difference reaction time and stained with indophenol indicator. (c) Timedependent $\mathrm{NH}_{3}$ concentration produced by Ti-COF catalyst at an applied potential of $0.7 \mathrm{~V}$.

The catalytic stability during the long-term NRR process is another key criterion for evaluating the performance of electrocatalysts. As presented in Figure S16a, during the long-term electrocatalytic NRR test for $12 \mathrm{~h}$, no obvious changes are observed in the current densities and FE values. Moreover, the catalytic stability of Ti-COF for the NRR is further confirmed by time-dependent electrolytic test under a constant applied voltage. Figure $\mathrm{S} 16 \mathrm{~b}$, c show that the time-dependent $\mathrm{NH}_{3}$ yield is increased as the electrolysis time prolongs. It means that $\mathrm{NH}_{3}$ can be produced sustainably by consuming the dissolved $\mathrm{N}_{2}$ in the electrolyte. 


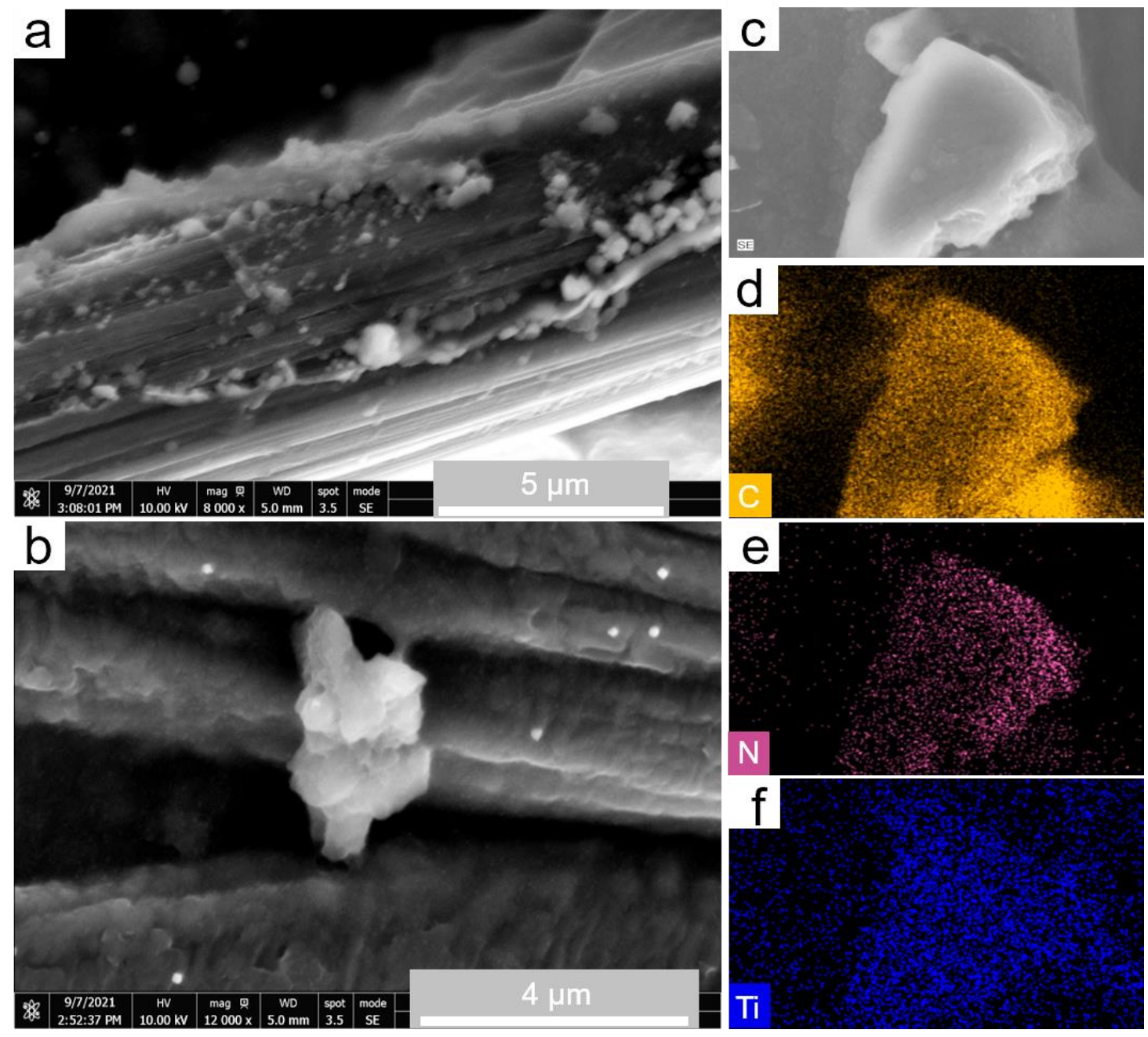

Figure S17. (a-c) SEM and (d-f) elemental mapping images of Ti-COF catalyst coated onto the CP after the electrochemical NRR at an applied potential of $-0.7 \mathrm{~V}$ ( $v s$. RHE) for $12 \mathrm{~h}$.

The structural integrity of Ti-COF after long-term electrocatalytic NRR test was also investigated. As presented in Figure S17, the surface morphology and elemental compositions of Ti-COF after the long-term NRR test for $12 \mathrm{~h}$ showed almost no change compared with those of Ti-COF at fresh state (Figure $1 \mathrm{~b}$ and S1a). The above analysis results indicate the better stability of Ti-COF during the NRR process. 

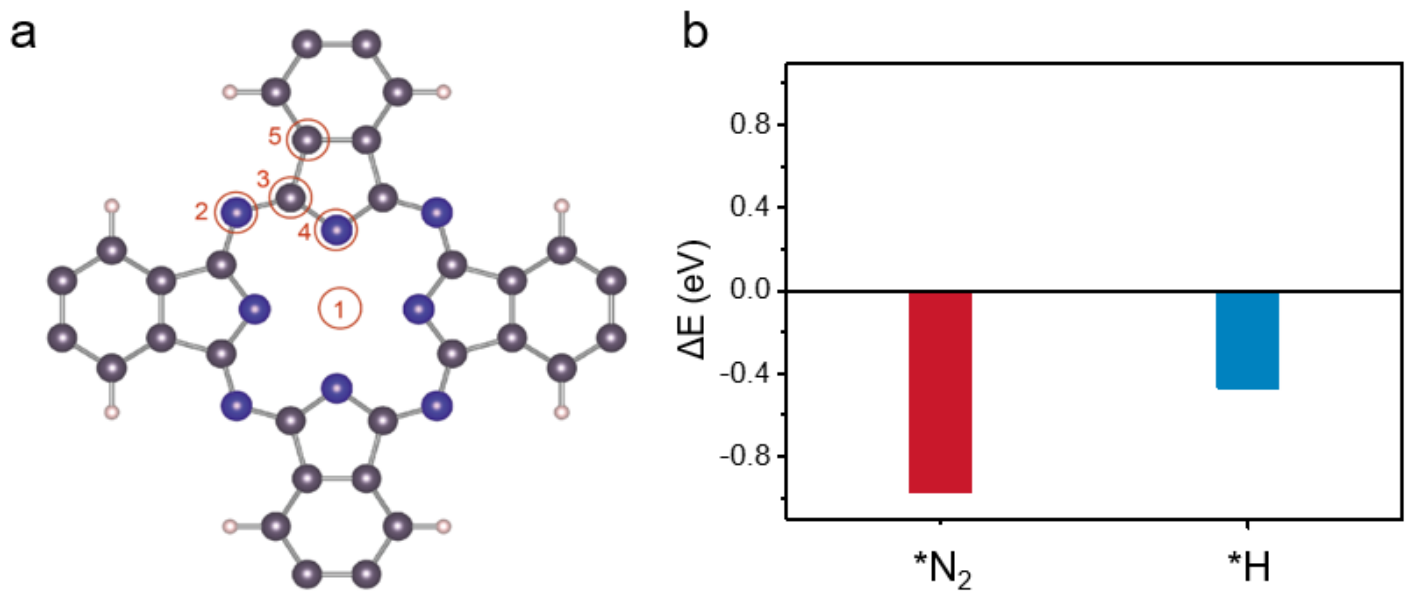

Figure S18. (a) Possible $\mathrm{N}_{2}$ adsorption sites on pristine COF and $\mathrm{M}-\mathrm{COF}(\mathrm{M}=\mathrm{Ti}, \mathrm{Cu}$ or Co). The red, blue and white spheres represent $\mathrm{C}, \mathrm{N}$ and $\mathrm{H}$ atoms, respectively. (b) The adsorption energies $(\Delta \mathrm{E})$ of $* \mathrm{~N}_{2}$ and $* \mathrm{H}$ species on Ti-COF.

Figure $\mathrm{S} 18 \mathrm{~b}$ shows that the adsorption energies of $* \mathrm{~N}_{2}$ and $* \mathrm{H}$ on Ti metal centre are -0.97 and $-0.47 \mathrm{eV}$, respectively. This means that the Ti metal centre is more conducive to adsorbing $* \mathrm{~N}_{2}$ rather than $* \mathrm{H}$. 


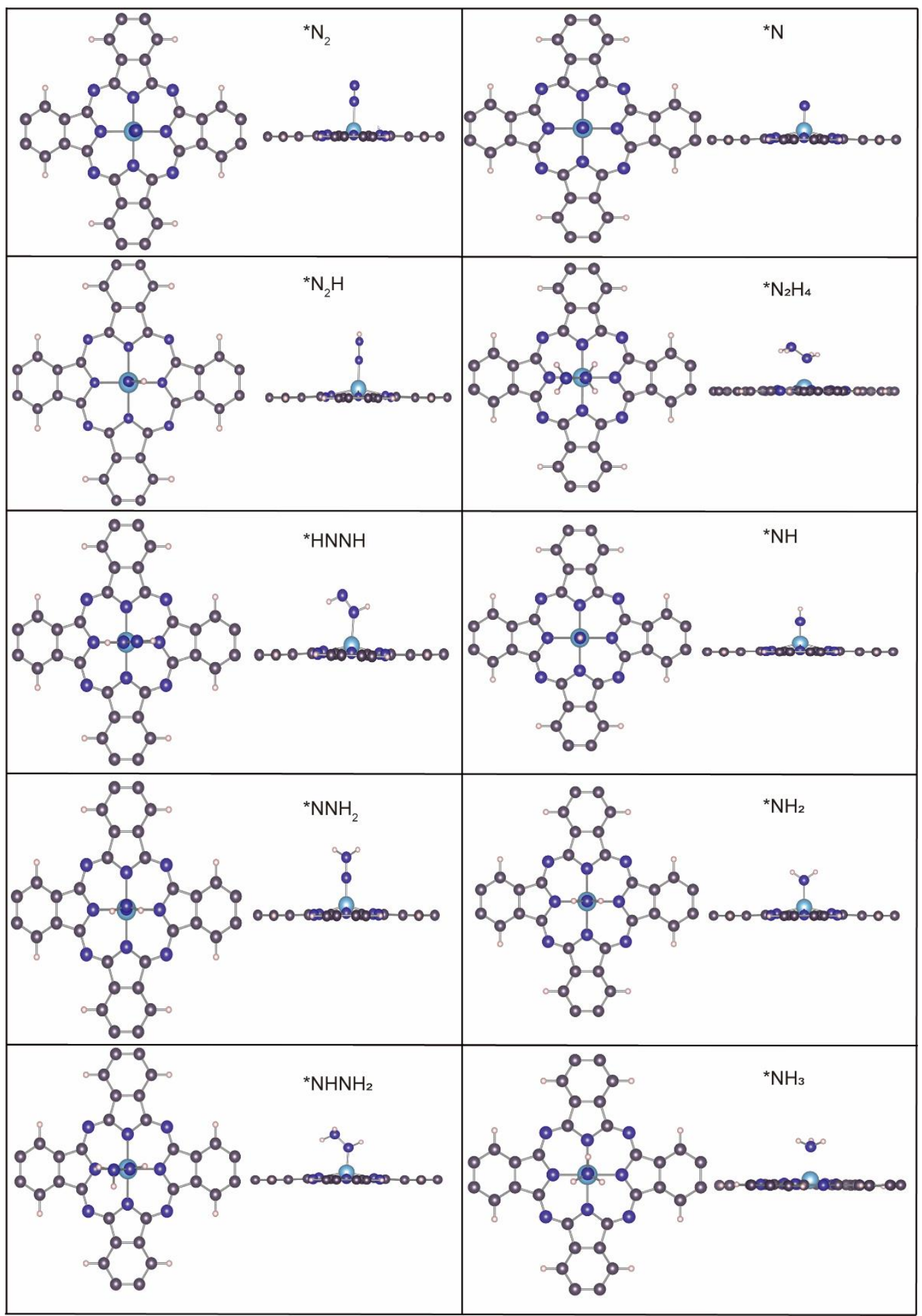

Figure S19. The adsorption models of different reaction intermediates on Ti-COF. The red, blue, white and light blue spheres represent $\mathrm{C}, \mathrm{N}, \mathrm{H}$ and Ti atoms, respectively. 
Table S1. Raman band locations $\left(\mathrm{cm}^{-1}\right)$ and peak assignments for $\mathrm{M}-\mathrm{COF}(\mathrm{M}=\mathrm{Ti}, \mathrm{Cu}$ or $\mathrm{Co}$ ) catalysts ${ }^{\mathrm{S} 1, \mathrm{~S} 2}$.

\begin{tabular}{|c|c|}
\hline Raman band location $\left(\mathrm{cm}^{-1}\right)$ & Peak assignment \\
\hline 685 & $\begin{array}{c}\text { Macrocycle vibration, } \mathrm{C}-\mathrm{N}-\mathrm{C} \text {, pyrrole expending, benzene } \\
\text { deformation }\end{array}$ \\
\hline 721 & Macrocycle vibration, $\mathrm{C}-\mathrm{H}$ out-of-plane bending \\
\hline 810 & $\mathrm{C}-\mathrm{N}-\mathrm{C}$ in-plane bending \\
\hline 1017 & $\mathrm{~N}-\mathrm{M}$ in-plane bending, ring stretching, benzene deformation \\
\hline 1110 & $\mathrm{C}-\mathrm{H}$ in-plane bending, isoindole N-M stretching \\
\hline 1180 & $\mathrm{C}-\mathrm{H}$ in-plane bending \\
\hline 1356 & Pyrrole N-M stretching \\
\hline 1430 & Isoindole stretching, $\mathrm{C}-\mathrm{H}$ in-plane bending, $\mathrm{C}-\mathrm{C}$ stretching \\
\hline 1541 & $\mathrm{C} \mathrm{sp}{ }^{2}$ vibration, $\mathrm{G}$ band \\
\hline 1615 & intravalley double-resonance process, D' band \\
\hline 2225 & Cyano group \\
\hline
\end{tabular}


Table S2. The accurate mass loadings of metal centers in Ti-COF, $\mathrm{Cu}-\mathrm{COF}$ and $\mathrm{Co}-$ COF determined by inductively-coupled plasma-optical emission spectrometer (ICPOES, Optima 5300DV).

\begin{tabular}{|c|c|c|c|}
\hline Sample & Ti (wt. $\%)$ & Cu (wt. \%) & Co (wt. \%) \\
\hline Ti-COF & 4.25 & -- & -- \\
\hline Cu-COF & -- & 5.10 & -- \\
\hline Co-COF & -- & -- & 7.40 \\
\hline
\end{tabular}


Table S3. NRR performance comparison of Ti-COF with other recently-reported NRR electrocatalysts under ambient conditions.

\begin{tabular}{|c|c|c|c|c|}
\hline Reference & Electrocatalyst & $\begin{array}{c}\mathrm{NH}_{3} \text { yield } \\
\left(\mu \mathrm{g} \cdot \mathrm{h}^{-1} \cdot \mathrm{mg}_{\text {cat. }}{ }^{-1}\right)\end{array}$ & FE (\%) & Electrolyte \\
\hline This work & Ti-COF & 26.98 & 34.62 & 0.05 M HCl \\
\hline Ref. S3 & Eex-COF/NC & 12.53 & 45.43 & $0.1 \mathrm{M} \mathrm{KOH}$ \\
\hline Ref. S4 & $\mathrm{Fe}-\mathrm{TiO}_{2}$ & 25.47 & 25.6 & $0.5 \mathrm{M} \mathrm{LiClO}_{4}$ \\
\hline Ref. S5 & Co-doped $\mathrm{MoS}_{2-\mathrm{x}}$ & 10.71 & 10 & $0.01 \mathrm{M} \mathrm{Na}_{2} \mathrm{SO}_{4}$ \\
\hline Ref. S6 & $\mathrm{NV}-\mathrm{W}_{2} \mathrm{~N}_{3}$ & 11.66 & 11.67 & $0.1 \mathrm{M} \mathrm{KOH}$ \\
\hline Ref. S7 & $\mathrm{Ru} \mathrm{SAs} / \mathrm{g}-\mathrm{C}_{3} \mathrm{~N}_{4}$ & 23.0 & 8.3 & $0.5 \mathrm{M} \mathrm{NaOH}$ \\
\hline Ref. S8 & $\mathrm{Au}_{6} / \mathrm{Ni}$ & 7.4 & 67.8 & $0.05 \mathrm{M} \mathrm{H}_{2} \mathrm{SO}_{4}$ \\
\hline Ref. S9 & $\mathrm{Au}-\mathrm{Fe}_{3} \mathrm{O}_{4}$ & 21.42 & 10.54 & $0.1 \mathrm{M} \mathrm{KOH}$ \\
\hline Ref. S10 & Pd cubes & 24.3 & 36.6 & $0.1 \mathrm{M} \mathrm{LiClO}_{4}$ \\
\hline Ref. S11 & $\mathrm{Fe} \mathrm{SAs} / \mathrm{MoS}_{2}$ & 8.63 & 18.8 & $0.5 \mathrm{M} \mathrm{K}_{2} \mathrm{SO}_{4}$ \\
\hline Ref. S12 & $\mathrm{Fe}-\mathrm{Cu}$ cluster & 9.86 & 34 & $0.001 \mathrm{M} \mathrm{H}_{2} \mathrm{SO}_{4}$ \\
\hline Ref. S13 & $\mathrm{Fe}_{3} \mathrm{Mo}_{3} \mathrm{C} / \mathrm{C}$ & 13.1 & 1.32 & $1 \mathrm{M} \mathrm{KOH}$ \\
\hline Ref. S14 & $\mathrm{Fe}-\mathrm{N} / \mathrm{C}-\mathrm{CNTs}$ & 34.83 & 9.28 & $0.1 \mathrm{M} \mathrm{KOH}$ \\
\hline Ref. S15 & Fe-Ni LDHs & 21.05 & 23 & $0.1 \mathrm{M} \mathrm{Na}_{2} \mathrm{SO}_{4}$ \\
\hline Ref. S16 & $\mathrm{Bi} \mathrm{NS}$ & 13.23 & 10.46 & $0.1 \mathrm{M} \mathrm{Na}_{2} \mathrm{SO}_{4}$ \\
\hline
\end{tabular}


Table S4. The adsorption energy $(\Delta \mathrm{E})$ of $\mathrm{N}_{2}$ at different possible adsorption sites of $\mathrm{M}$ $\mathrm{COF}(\mathrm{M}=\mathrm{Ti}, \mathrm{Cu}$ or $\mathrm{Co})$ and pristine $\mathrm{COF}$.

\begin{tabular}{|c|c|c|c|c|c|}
\hline Electrocatalyst & $\boldsymbol{\Delta} \mathbf{E}_{1}(\mathrm{eV})$ & $\boldsymbol{\Delta} \mathbf{E}_{\mathbf{2}}(\mathrm{eV})$ & $\boldsymbol{\Delta} \mathbf{E}_{\mathbf{3}}(\mathrm{eV})$ & $\boldsymbol{\Delta} \mathbf{E}_{\mathbf{4}}(\mathrm{eV})$ & $\boldsymbol{\Delta} \mathbf{E}_{\mathbf{5}}(\mathrm{eV})$ \\
\hline Ti-COF & $\mathbf{- 0 . 9 7}$ & -0.03 & -0.03 & -0.03 & -0.03 \\
\hline Cu-COF & -0.02 & $\mathbf{- 0 . 0 7}$ & $\mathbf{- 0 . 0 7}$ & $-\mathbf{0 . 0 7}$ & -0.06 \\
\hline Co-COF & 0.07 & $\mathbf{- 0 . 0 3}$ & $\mathbf{- 0 . 0 3}$ & 0.15 & $\mathbf{- 0 . 0 3}$ \\
\hline Pristine COF & $\mathbf{- 0 . 0 9}$ & -0.08 & -0.07 & 1.92 & -0.07 \\
\hline
\end{tabular}


Table S5. Computed total energies (EDFT), entropies $\left(\mathrm{TS}_{\mathrm{t}+\mathrm{r}+\mathrm{v}}\right)$, zero point energy $(\mathrm{ZPE})$ and Gibbs free energy $(\mathrm{G})$, in $\mathrm{eV}$, for the gas phase $\mathrm{N}_{2}, \mathrm{H}_{2}, \mathrm{NH}_{3}$ species and reaction intermediates on Ti-COF. T $=298.15 \mathrm{~K}, \mathrm{P}=1$ bar.

\begin{tabular}{|c|c|c|c|c|}
\hline Species & $\mathbf{E}_{\text {DFT }}$ & $\mathbf{T S} \mathbf{S}_{\mathrm{t}+\mathrm{r}+\mathrm{v}}$ & ZPE & $\mathbf{G}$ \\
\hline $\mathrm{N}_{2}(\mathrm{~g})$ & -16.61 & 0.59 & 0.15 & -16.96 \\
\hline $\mathrm{H}_{2}(\mathrm{~g})$ & -6.76 & 0.40 & 0.27 & -6.81 \\
\hline $\mathrm{NH}_{3}(\mathrm{~g})$ & -19.54 & 0.60 & 0.91 & -19.12 \\
\hline$* \mathrm{~N}_{2}$ & -288.15 & 0.16 & 0.20 & -288.04 \\
\hline$* \mathrm{~N}_{2} \mathrm{H}$ & -290.90 & 0.18 & 0.46 & -290.53 \\
\hline *NHNH & -294.50 & 0.21 & 0.81 & -293.81 \\
\hline$* \mathrm{NNH}_{2}$ & -295.01 & 0.19 & 0.80 & -294.31 \\
\hline$* \mathrm{NHNH}_{2}$ & -298.86 & 0.23 & 1.12 & -297.85 \\
\hline$* \mathrm{~N}$ & -277.48 & 0.08 & 0.06 & -277.46 \\
\hline$* \mathrm{NH}_{2} \mathrm{NH}_{2}$ & -302.37 & 0.18 & 1.50 & -300.96 \\
\hline$* \mathrm{NH}$ & -283.58 & 0.09 & 0.35 & -283.28 \\
\hline$* \mathrm{NH}_{2}$ & -287.97 & 0.13 & 0.65 & -287.38 \\
\hline$* \mathrm{NH}_{3}$ & -291.61 & 0.17 & 1.03 & -290.67 \\
\hline
\end{tabular}


Table S6. Computed d-band center and the state of charge for metal centres in M-COF $(\mathrm{M}=\mathrm{Ti}, \mathrm{Cu}$ and $\mathrm{Co})$.

\begin{tabular}{|c|c|c|}
\hline Metal & d-band center & State of charge $\left(\mathbf{e}^{-1}\right)$ \\
\hline $\mathrm{Ti}(\mathrm{Ti}-\mathrm{COF})$ & 0.63 & +1.67 \\
\hline $\mathrm{Ti}\left(\mathrm{Ti}^{-} \mathrm{COF}^{*} \mathrm{~N}_{2}\right)$ & 0.49 & +2.29 \\
\hline $\mathrm{Cu}(\mathrm{Cu}-\mathrm{COF})$ & -3.22 & +0.91 \\
\hline $\mathrm{Co}(\mathrm{Co}-\mathrm{COF})$ & -0.92 & +1.01 \\
\hline
\end{tabular}




\section{Supporting References}

(S1) Alessio, P.; Rodríguez-Méndez, M.; Saez, J.; Constantino, J. Iron phthalocyanine in non-aqueous medium forming layer-by-layer films: growth mechanism, molecular architecture and applications, Phys. Chem. Chem. Phys. 2010, 12, 39723983.

(S2) Peng, P.; Shi, L.; Huo, F.; Zhang, S.; Mi, C.; Cheng, Y.; Xiang, Z. In situ charge exfoliated soluble covalent organic framework directly used for $\mathrm{Zn}$-air flow battery, ACS Nano 2019, 13, 878-884.

(S3) Liu, S.; Wang, M.; Qian, T.; Ji, H.; Liu, J.; Yan, C. Facilitating nitrogen accessibility to boron-rich covalent organic frameworks via electrochemical excitation for efficient nitrogen fixation, Nat. Commun. 2019, 10, 1-9.

(S4) Wu, T.; Zhu, X.; Xing, Z.; Mou, S.; Li, C.; Qiao, Y.; Liu, Q.; Luo, Y.; Shi, X.; Zhang, Y.; Sun, X. Greatly improving electrochemical $\mathrm{N}_{2}$ reduction over $\mathrm{TiO}_{2}$ nanoparticles by iron doping, Angew. Chem. 2019, 58, 18449-18453.

(S5) Zhang, J.; Tian, X.; Liu, M.; Guo, H.; Zhou, J.; Fang, Q.; Liu, Z.; Wu, Q.; Lou, J. Cobalt-Modulated Molybdenum-Dinitrogen Interaction in $\mathrm{MoS}_{2}$ for Catalyzing Ammonia Synthesis, J. Am. Chem. Soc. 2019, 141, 19269-19275.

(S6) Jin, H.; Li, L.; Liu, X.; Tang, C.; Xu, W.; Chen, S.; Song, L.; Zheng, Y.; Qiao, S. Nitrogen vacancies on $2 \mathrm{D}$ layered $\mathrm{W}_{2} \mathrm{~N}_{3}$ : A stable and efficient active site for nitrogen reduction reaction, $A d v$. Mater. 2019, 31, 1902709-1902716.

(S7) Yu, B.; Li, H.; White, J.; Donne, S.; Yi, J.; Xi, S.; Fu, Y.; Henkelman, G.; Yu, H.; Chen, Z.; Ma, T. Tuning the catalytic preference of ruthenium catalysts for nitrogen reduction by atomic dispersion, Adv. Funct. Mater. 2020, 30, 19056651905675 .

(S8) Xue, Z.; Zhang, S.; Lin, Y.; Su, H.; Zhai, G.; Han, J.; Yu, Q.; Li, X.; Antonietti, M.; Chen, J. Electrochemical reduction of $\mathrm{N}_{2}$ into $\mathrm{NH}_{3}$ by donor-acceptor couples of $\mathrm{Ni}$ and Au nanoparticles with a 67.8\% Faradaic efficiency, J. Am. Chem. Soc. 2019, $141,14976-14980$. 
(S9) Zhang, J.; Ji, Y.; Wang, P.; Shao, Q.; Li, Y.; Huang, X. Adsorbing and Activating $\mathrm{N}_{2}$ on Heterogeneous $\mathrm{Au}-\mathrm{Fe}_{3} \mathrm{O}_{4}$ Nanoparticles for $\mathrm{N}_{2}$ Fixation, Adv. Funct. Mater. 2020, 30, 1906579-1906586.

(S10) Zhao, H.; Zhang, D.; Li, H.; Qi, W.; Wu, X.; Han, Y.; Cai, W.; Wang, Z.; Lai, J. P.; Wang, L. Exposure of Definite Palladium Facets Boosts Electrocatalytic Nitrogen Fixation at Low Overpotential, Adv. Energy Mater. 2020, 10, 20021312002136.

(S11) Su, H.; Chen, L.; Chen, Y.; Si, R.; Wu, Y.; Wu, X.; Geng, Z.; Zhang, W.; Zeng, J. Single Atoms of Iron on $\mathrm{MoS}_{2}$ Nanosheets for $\mathrm{N}_{2}$ Electroreduction into Ammonia, Angew. Chem. 2020, 59, 20411-20416.

(S12) Wang, X.; Qiu, S.; Feng, J.; Tong, Y.; Zhou, F.; Li, Q.; Song, L.; Chen, S.; Wu, K.; Su, P.; Ye, S.; Hou, F.; Dou, S.; Liu, H.; Lu, G.; Sun, C.; Liu, J.; Liang, J. Confined $\mathrm{Fe}-\mathrm{Cu}$ Clusters as Sub-Nanometer Reactors for Efficiently Regulating the Electrochemical Nitrogen Reduction Reaction, Adv. Mater. 2020, 32, e2004382.

(S13) Cheng, H.; Cui, P.; Wang, F.; Ding, L.; Wang, H. High efficiency electrochemical nitrogen fixation achieved with a lower pressure reaction system by changing the chemical equilibrium, Angew. Chem. 2019, 58, 15541-15547.

(S14) Wang, Y.; Cui, X.; Zhao, J.; Jia, G.; Gu, L.; Zhang, Q.; Meng, L.; Shi, Z.; Zheng, L.; Wang, C.; Zhang, Z.; Zheng, W. Rational design of Fe-N/C hybrid for enhanced nitrogen reduction electrocatalysis under ambient conditions in aqueous solution, ACS Catal. 2018, 9, 336-344.

(S15) Liu, Y.; Tang, L.; Dai, J.; Yu, J.; Ding, B. Promoted Electrocatalytic Nitrogen Fixation in Fe-Ni Layered Double Hydroxide Arrays Coupled to Carbon Nanofibers: The Role of Phosphorus Doping, Angew. Chem. 2020, 132, 1372513729 .

(S16) Li, L.; Tang, C.; Xia, B.; Jin, H.; Zheng, Y.; Qiao, S. Two-dimensional mosaic bismuth nanosheets for highly selective ambient electrocatalytic nitrogen reduction, ACS Catal. 2019, 9, 2902-2908. 